\title{
Como identificar a lógica interna das práticas motrizes de interação? Uma proposta de ferramenta de análise a partir da Praxiologia Motriz ${ }^{1}$
}

\author{
How to identify the internal logic of motor practices of interaction? An analysis tool proposal \\ from the Motor Praxiology
}

\begin{abstract}
¿Cómo identificar la lógica interna de las prácticas motrices de interacción? Una propuesta de herramienta de análisis desde la Praxiología Motriz
\end{abstract}

\author{
Felipe Menezes Fagundes ${ }^{\mathrm{I}}$, Natiele Follmann ${ }^{\mathrm{II}}$, Vanessa Ines Wenzel ${ }^{\mathrm{III}}$
}

\begin{abstract}
Resumo
Este estudo, que se caracteriza como uma pesquisa teórica e de cunho exploratório, tem o objetivo de propor uma ferramenta de análise dos principais elementos da lógica interna das práticas motrizes, a partir da Praxiologia Motriz. Elaborada a fim de subsidiar a prática pedagógica de professores de Educação Física, a ferramenta de análise foi estruturada em duas etapas: a primeira destinada à análise propriamente dita da lógica interna das práticas motrizes de interação; e a segunda dedicada à apresentação de um guia didático para o desenvolvimento de determinada prática a partir das características evidenciadas na análise.
\end{abstract}

Palavras-chave: Praxiologia Motriz; Lógica Interna; Ensino; Práticas Motrizes

\begin{abstract}
This study, which is characterized as a theoretical and exploratory research, aims to propose a tool to analyze the main elements of the internal logic of motor practices, based on the Motor Praxiology. The analysis tool was designed to support the pedagogical practice of Physical Education teachers and it was structured in two stages: the first one aimed to analyze the internal logic of the interaction motor practices; and the second one dedicated to the presentation of a didactic guide for the development of a certain practice based on the characteristics evidenced in the analysis.
\end{abstract}

Keywords: Motor Praxiology; Internal Logic; Teaching; Motor Practices

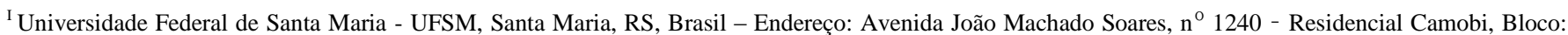
B4, Apartamento: 414, Santa Maria - RS, CEP: 97110-000 - e-mail: felipemfagundes@live.com

${ }^{\text {II }}$ Universidade Federal de Santa Maria - UFSM, Santa Maria, RS, Brasil - e-mail: nfollmann@ yahoo.com.br

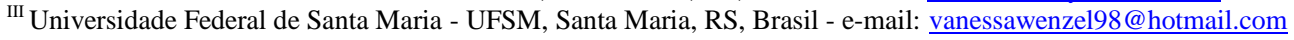

${ }^{1}$ Este trabalho contou com apoio financeiro da CAPES/CNPq
} 


\section{Resúmen}

Este estudio, que se caracteriza como una investigación teórica y exploratoria, tiene como objetivo proponer una herramienta de análisis de los principales elementos de la lógica interna de las prácticas motrices, desde la Praxiología Motriz. Elaborada para apoyar la práctica pedagógica de profesores, la herramienta de análisis fue estructurada en dos etapas: la primera destinada al análisis propiamente dicha de la lógica interna de las prácticas motrices de interacción; y la segunda dedicada a la presentación de una guía didáctica para el desarrollo de determinada práctica a partir de las características evidenciadas en el análisis.

Palavras clave: Praxiología Motriz; Lógica Interna; Enseñanza; Prácticas motrices

\section{Introdução}

Os debates acadêmicos atuais na área sociocultural da Educação Física, embasados nas discussões de Kunz (2006), Bracht (1999), Soares et al. (1992), entre outros autores, vêm se consolidando cada vez mais no cenário científico nacional, em especial no que se referem as suas concepções pedagógicas e nas questões de ensinoaprendizagem. Essas recentes discussões, aparentemente, levam a crer que há um consenso no que se refere à tarefa da Educação Física: o ensino das manifestações que compõem a Cultura de Movimento, a Cultura Corporal de Movimento ou a Cultura Corporal, dentre outras denominações teóricas possíveis (DAÓLIO, 2004). Isso faz com que se identifique um denominador comum a todas essas visões e concepções da área, que está centrada na própria legitimação da Educação Física como geradora de cultura.

Por se tratarem de manifestações socioculturais, perpetuadas de geração em geração, tem-se uma necessidade do estabelecimento de regras que padronizem e, em especial, possibilitem a materialização desses fenômenos. Sejam essas manifestações mais ou menos institucionalizadas (esporte e jogo, respectivamente), suas existências estão condicionadas aos seus sistemas de regras específicos, os quais lhes darão lógicas estruturais de funcionamento (PARLEBAS, 2001).

Ao considerar esse entendimento, essa dinâmica relacional das manifestações passa a ser um dos elementos principais do processo de ensino-aprendizagem da Educação Física, ao se consolidarem como propriedades genuínas dessas manifestações que compõem essa área de conhecimento. Essa compreensão já se faz presente na própria Base Nacional Comum Curricular (BNCC), que apresenta a organização interna como elemento comum da prática corporal, pautada por uma lógica específica, que, segundo o documento, deve ser conteúdo das aulas de Educação Física (BRASIL, 2018).

Tendo em vista o processo de ensino-aprendizagem dessas dinâmicas de funcionamento, em especial as que contemplam interações motrizes de cooperação e/ou oposição, faz-se necessário um olhar mais aprofundado quanto a esses elementos. Assim, algumas dúvidas se estabelecem a partir desse cenário: como identificar, analisar e sistematizar essa organização interna das práticas corporais? Quais ferramentas os professores precisam para delimitar esses conhecimentos? Uma possibilidade de resposta a essas questões pode estar situada no arcabouço 
teórico da Praxiologia Motriz, uma teoria cientificamente estruturada para compreensão da lógica interna de jogos e esportes, criada pelo professor Pierre Parlebas.

Dispondo de uma série de conceitos e modelos de análise, como o Sistema de Classificação CAI e os Universais, a Praxiologia Motriz apresenta potencial como uma matriz de análise dessas manifestações socioculturais, entendidas, por essa teoria, como práticas motrizes. No entanto, essa gama de conhecimentos contemplados pela Praxiologia Motriz é complexa em um primeiro momento. Para consolidar suas proposições, Parlebas (2001) precisou fundamentar seus estudos sobre as práticas motrizes na Semiótica, na Sociologia, na Matemática e na Psicologia, com o intuito de constituir critérios científicos de análise.

A partir desses critérios elaborados por Parlebas (2001), vários estudos se apropriaram desses conhecimentos para melhor compreender a lógica interna de diversas práticas motrizes como, por exemplo, Voleibol, Jogos Tradicionais, Futebol, entre outros (RIBAS, 2014; FAGUNDES; RIBAS, 2017; OLIVEIRA; RIBAS; GOMES-DA-SILVA 2018; LANES, 2018; FRANCHI, 2017; SILVA, 2015; MARQUES FILHO, 2017). Essas pesquisas constataram a relevância do conhecimento praxiológico para a compreensão da lógica interna dessas práticas motrizes, inserindo novos e relevantes elementos ao processo de ensino-aprendizagem.

Com base nos resultados apresentados nesses estudos que se embasaram nos conhecimentos da Praxiologia Motriz, constatou-se a necessidade de elaborar um instrumento que possibilitasse, de forma simplificada e objetiva, a análise desses elementos das práticas motrizes de interação, para subsidiar a prática pedagógica de professores in loco. A partir dessa problemática, o objetivo deste estudo é propor uma ferramenta de análise dos principais elementos da lógica interna das práticas motrizes, a partir da Praxiologia Motriz.

\section{Metodologia}

Este estudo caracteriza-se como uma pesquisa teórica, que, segundo Demo (2000, p. 20), é "dedicada a reconstruir teoria, conceitos, ideias, ideologias, polêmicas, tendo em vista, em termos imediatos, aprimorar fundamentos teóricos". A pesquisa pode ainda ser considerada de cunho exploratório, visto que busca "desenvolver, esclarecer e modificar conceitos e ideias, tendo em vista a formulação de problemas mais precisos ou hipóteses pesquisáveis para estudos posteriores" (GIL, 2008, p. 27).

Para atingir o objetivo estabelecido neste estudo, utilizou-se a Praxiologia Motriz, que apresenta um conjunto de conhecimentos que auxiliam na compreensão do funcionamento dos jogos e esportes, bem como das demais práticas motrizes. Dentre eles destaca-se o Sistema de Classificação CAI, que é um instrumento de análise da Praxiologia Motriz que permite conhecer a essência de um jogo e/ou esporte. Ao criar o Sistema de Classificação CAI, Parlebas (2001) adotou a compreensão do jogo como um sistema, considerando suas partes e suas relações recíprocas. 
Contudo, somente a partir do Sistema de Classificação CAI não é possível conhecer os comportamentos individuais dos participantes da prática motriz, mas sim classificar e ordenar as práticas de acordo com as interações existentes em sua lógica interna. Com essa prerrogativa, a Praxiologia Motriz dispõe de outras ferramentas que auxiliam no desvelar das características dessas práticas motrizes, dos quais se salientam os conceitos lógica interna, interação motriz e comunicação motriz.

A partir do Sistema de Classificação CAI e dos demais conhecimentos praxiológicos, foi elaborada uma ferramenta de análise dos principais elementos da lógica interna das práticas motrizes, com a intenção de auxiliar o professor no processo de ensino-aprendizagem, oferecendo subsídios que facilitem esse processo. Com o intuito de saber se a ferramenta se adequa ao propósito indicado, a mesma foi enviada para 19 professores de Educação Física. Obteve-se cinco respostas, sendo elas de um doutor, três mestres e um mestrando, com algumas considerações pontuais sobre a ferramenta e que foram consideradas para a elaboração final, a qual será apresentada neste trabalho.

\section{Praxiologia Motriz: base teórica para o estudo da lógica interna}

A Praxiologia Motriz vem sendo desenvolvida a mais de 30 anos na França, por Pierre Parlebas, professor de Educação Física, com formação e influência científica em outras áreas de conhecimento, como a Matemática, a Linguística, a Sociologia e a Semiótica (RIBAS, 2014). Parlebas (2001, p. 354) conceitua a Praxiologia Motriz como "Ciência da Ação Motriz e especialmente das condições, modos de funcionamento e resultado de seu desenvolvimento". A conceituação de Parlebas (1988) quanto a Praxiologia Motriz mostra-se complexa em um primeiro momento, ao considerar que essa definição atêm-se à necessidade de compreensão do conceito de Ação Motriz, matéria-prima dos debates e análises praxiológicos. Nesse sentido, Lagardera e Lavega (2003) simplificam a delimitação teórica da Praxiologia Motriz, caracterizando-a como o estudo da lógica interna das práticas motrizes.

A lógica interna constitui-se da forma como está organizada uma prática motriz. Por sua raiz epistemológica Estruturalista, a Praxiologia Motriz compreende as manifestações da cultura corporal de movimento como sistemas praxiológicos (PARLEBAS, 1988). Parlebas (2001) define lógica interna como um conjunto de características que remetem consequências na realização das ações motrizes. Com esse pressuposto, cada uma dessas manifestações apresentará uma organização distinta, a qual é subsidiada pelas regras estabelecidas para essa prática motriz, a qual gera uma lógica interna específica, carregada de suas características, como uma espécie de identidade motriz que a torna singular e complexa.

Em face de uma lógica interna, os jogadores de qualquer prática motriz, ao interagirem com esse sistema praxiológico, produzem determinadas ações motrizes. Parlebas (2001, p. 41) conceitua a ação motriz como "processo de realização das condutas motrizes de um ou vários sujeitos que atuam em uma situação motriz determinada". Nesse sentido, a ação motriz se caracteriza como um produto motor da prática motriz, a matéria prima da Praxiologia Motriz, o substrato da relação jogador - jogo. Cabe salientar que o conceito de ação motriz ultrapassa a perspectiva dualógica entre técnica e tática de mecanização dos gestos motores, pois seu espectro 
abrange elementos como antecipação, decisão, interação e leitura, todos vinculados à lógica interna em questão, não se limitando a descrição de movimentos ou descrições técnicas (PARLEBAS, 2001; LAGARDERA; LAVEGA, 2003).

Mas como que se identificam as características da lógica interna de uma prática motriz? Para sua identificação, é necessário que, a partir do corpo de regras da prática motriz, se evidencie as possibilidades de relação que um ou mais jogadores podem (ou não podem) estabelecer com os quatro pilares da lógica interna: demais jogadores, material, espaço e tempo. Cada uma dessas possibilidades de interação do jogador apontam para a sistematização gerada pelo corpo de regras da prática motriz e auxiliam a esclarecer a trama de relações estabelecidas nesse sistema praxiológico em questão.

A pertinência de estudos e discussões referentes à lógica interna está enraizada profundamente no conceito de interação motriz (PARLEBAS, 1988). Parte-se do pressuposto que o jogador, ao atuar no sistema praxiológico, estabelece relação direta com os componentes dessa dita organização intrínseca. Parlebas (2001, p. 269) define a ocorrência de uma interação motriz quando "[...] durante a realização de uma tarefa motriz, o comportamento motor de um indivíduo influi de maneira observável no de outro ou vários dos demais participantes".

Nesse sentido, o conceito de interação motriz faz menção à forma como as ações motrizes serão executadas em relação aos companheiros e aos adversários no contexto do jogo (PARLEBAS, 1998; LAGARDERA; LAVEGA, 2003). Ela é a responsável por guiar todas as ações que serão realizadas no jogo, sob a égide da comunicação (cooperação) e/ou da contracomunicação (oposição). A comunicação será manifestada toda vez em que o comportamento motor objetivar a facilitação das ações motrizes e dos processos de leitura do(s) outro(s) jogador(es). Já a contracomunicação, como sua denominação suscita, está vinculada ao processo de dificultar ações e interpretações do comportamento motor do(s) outro(s) jogador(es) (RIBAS, 2014). Com esse entendimento, se atrela significado e intencionalidade às ações realizadas pelos jogadores em determinados contextos do jogo, salientando a necessidade dos processos interpretativos e de tomada de decisão nas práticas motrizes de interação.

Esses processos de interpretação são extremamente complexos, entretanto substanciais para a realização de qualquer ação em um jogo ou esporte que apresente interação motriz. Fagundes e Ribas (2017) afirmam que o sucesso interventivo nas situações de jogos está vinculado à capacidade de leitura dos jogadores e tomada de decisão, principalmente quando se compreende que a sua própria ação é emissora de mensagens e que torná-las mais obscuras aos adversários amplia a imprevisibilidade e dificulta as ações do adversário, acarretando em vantagens consideráveis nas situações do jogo. Ao mesmo tempo, facilitar esses processos para os companheiros potencializa a atuação da equipe como um todo, principalmente no que tange às organizações estratégicas.

Como já, brevemente, mencionado, o Sistema de Classificação CAI é um dos instrumentos de análise da Praxiologia Motriz que permite conhecer a essência de um jogo e/ou esporte. Logo, os comportamentos individuais não serão conhecidos, mas sim as interações que existem dentro de determinados jogos e esportes (PARLEBAS, 1988). 
Para organizar os jogos e esportes, o Sistema de Classificação CAI parte de dois critérios, que se referem ao entorno físico e à forma de interação dos participantes (cooperação e/ou oposição) (RIBAS, 2014). Ao mencionar o entorno físico, tem-se as seguintes possibilidades: 1. Meio estável ou padrão e 2. Meio instável. Já no que se refere à forma de interação, tem-se quatro grupos: 1. Sem interação ou psicomotriz. 2. Com interação de oposição ou sociomotriz de oposição. 3. Com interação de cooperação ou sociomotriz de cooperação e 4. Com interação de oposição e cooperação simultânea ou sociomotriz de cooperação-oposição. É a partir destas interações entre os participantes e em relação ao entorno físico que surge a denominação da sigla CAI, cujas iniciais referemse a Companheiro, Adversário e Incerteza (RIBAS, 2014).

Quanto ao entorno físico, sua interferência se dá na organização das condutas motrizes do jogador ou participante, isso ocorre a partir da informação que o mesmo deduz por intermédio da relação com este meio. A leitura constante não precisará ser realizada pelo jogador em uma atividade em meio estável, visto que, nestas situações, o entorno físico é padrão, com espaços próprios, medidas e piso especificamente regulamentados. Os esportes coletivos, as ginásticas e as lutas são práticas motrizes que apresentam essa característica. Já nas atividades realizadas em meio instável o jogador "terá de realizar uma constante leitura do meio para adequar suas condutas motrizes a essa prática" (RIBAS, 2014, p. 30). Surfe, vôlei de praia e iatismo são alguns exemplos de práticas em meio instável.

Quanto a presença ou não de interações entre os participantes, as atividades estão divididas em dois grupos: 1. Situações psicomotrizes e 2. Situações sociomotrizes (cooperação e oposição). Salienta-se que esta pesquisa é referente a este grupo de situações, as com interações sociomotrizes. O primeiro grupo corresponde às "situações nas quais o participante intervém sozinho, sem interagir com companheiros ou adversários" (LAGARDERA e LAVEGA, 2008, p. 84), como, por exemplo, em provas de atletismo (corrida de 100 metros, lançamento de disco). Já as situações sociomotrizes são aquelas onde existem interações entre os participantes, as quais poderão ser de: a) cooperação (ou comunicação motriz), b) oposição (ou contracomunicação motriz) ou c) cooperação e oposição. Nas situações de cooperação ou comunicação motriz a interação ocorre entre, ao menos, duas pessoas que cooperam entre si para chegar ao mesmo objetivo. Nas situações de oposição ou contracomunicação motriz a interação ocorre com, ao menos, um adversário. Já nas atividades que são de cooperação e oposição o participante irá cooperar com, pelo menos, um companheiro e se opor há, no mínimo, um adversário. Observe exemplos destas interações na Figura 1, a seguir: 
Figura 1- Sistema de Classificação CAI

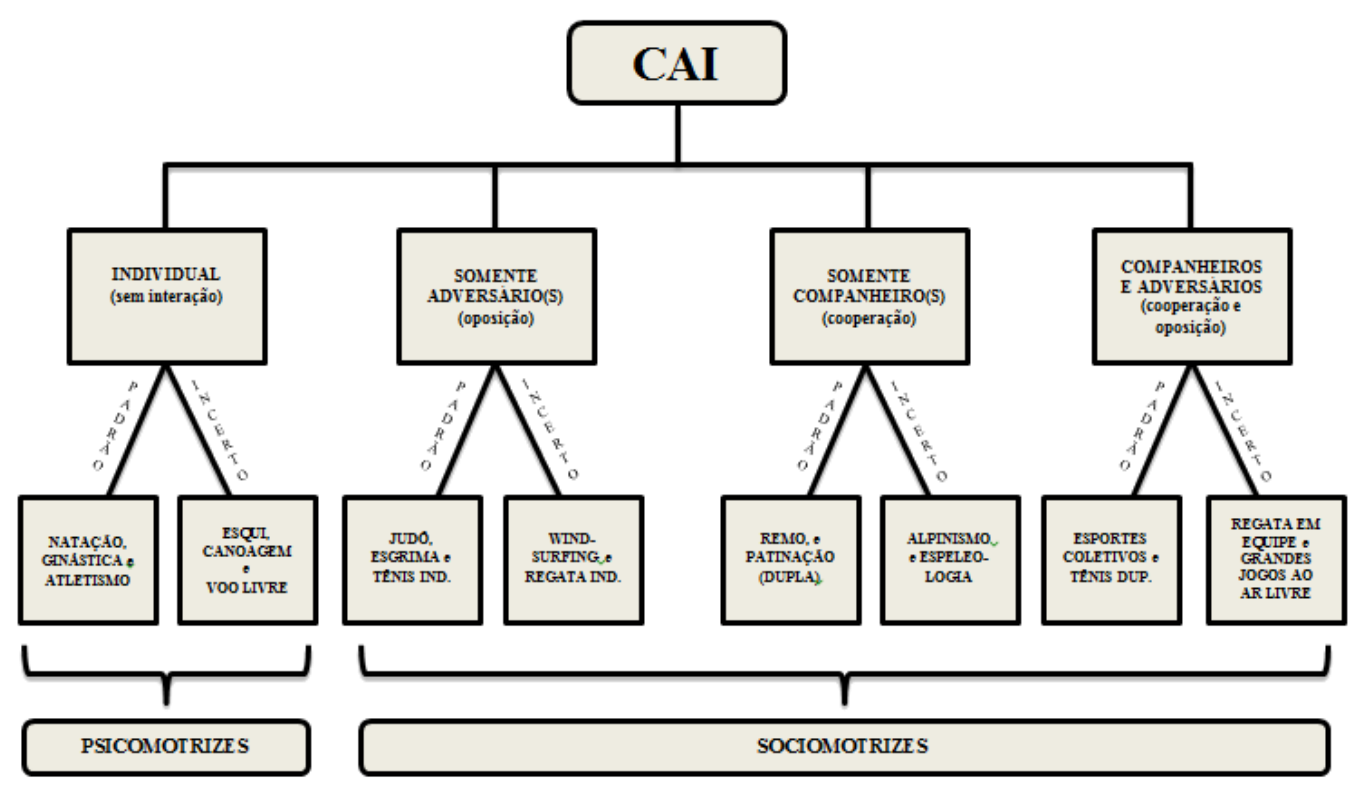

Fonte: Elaborada pelos autores, adaptada de Ribas (2014, p. 31)

Conhecidas as interações expressas em um sistema praxiológico, a partir da proposição do Sistema de Classificação CAI, torna-se possível mapear as possibilidades de ação dos jogadores, a partir dos papéis e subpapéis estabelecidos pela prática motriz. Os papéis são constituídos por um conjunto de comportamentos pautado nos direitos e proibições explicitados na lógica interna de cada prática motriz, definindo as ações motrizes exequíveis pelos jogadores, enquanto que os subpapéis definem-se como as unidades básicas de cada papel, ou seja, as próprias possibilidades de ação (PARLEBAS, 2001; LAGARDERA, LAVEGA, 2003).

Para essa análise, é substancial apoiar-se às regras do jogo, identificando as concessões e as sanções possíveis de cada jogador, no sentido de identificar sua função (papel) e mapear suas possibilidades de ação (subpapel). Lagardera e Lavega (2003) e Hernández Moreno e Rodríguez Ribas (2004) apontam que se devem considerar as relações entre os jogadores, com o espaço, com o tempo e com o material das práticas motrizes para o estabelecimento dos papéis e dos subpapéis que ela concede.

As contribuições pedagógicas dos papéis e subpapéis centram-se na compreensão dos alunos em relação a sua função no jogo, bem como em salientar que a organização das equipes está vinculada a essas possibilidades de ação. Esse esclarecimento quanto aos papéis e subpapéis fornece sentido ao que é realizado no contexto do jogo, o que auxilia na compreensão da lógica interna (FAGUNDES; RIBAS, 2017). Além disso, o professor pode estruturar unidades didáticas, partindo da estruturação estabelecida pelos papéis/subpapéis que a prática motriz concede, iniciando pelos aspectos estruturais da lógica interna, chegando até suas ações motrizes específicas (LAGARDERA; LAVEGA, 2003). A partir dos conceitos referentes a papéis e subpapéis, é possível identificar as 
situações específicas da prática motriz, as funções dos jogadores e as ações motrizes correspondentes, vinculados especificamente à lógica interna.

No caso do Voleibol, por exemplo, são identificados quatro papéis específicos: sacador, defensor, atacante e líbero. A delimitação de cada um desses papéis está vinculada aos direitos e proibições que o corpo de regras deste esporte concede aos jogadores. Cada papel, a partir de suas características, irá apresentar subpapéis específicos. Por exemplo, apenas o papel do sacador terá o direito de realizar o subpapel sacar, assim como apenas o papel de atacante tem o direito de assumir o subpapel bloquear.

É importante delimitar que há uma diferença entre o subpapel e a execução da ação motriz propriamente dita, ou seja, o subpapel é assumido e sua materialização poderá acontecer por meio de diferentes ações motrizes, vinculadas às situações de jogo. Retomando o exemplo do Voleibol, o mesmo subpapel atacar pode ser manifestado por meio da ação motriz da cortada (a mais usual) ou por qualquer outra ação motriz do jogo (toque, manchete ou outro recurso), não deixando de se assumir o subpapel atacar. Isso significa que atacar não corresponde exclusivamente a realização de uma cortada, mas sim da tentativa de pontuar, independente da ação motriz utilizada.

Com base nos conhecimentos da Praxiologia Motriz e na sua potencialidade científica como teoria de análise da lógica interna, elaborou-se uma ferramenta de análise da lógica interna de práticas motrizes de interação, com intuito de traduzir esses conceitos em um instrumento didático que auxilie a prática pedagógica de professores e profissionais da Educação Física. Na próxima seção deste estudo, será apresentado esse formulário, bem como algumas considerações para o uso dessa ferramenta por professores e profissionais da área.

\section{Proposta de ferramenta de análise da lógica interna das práticas motrizes de interação}

A fim de subsidiar a prática pedagógica de professores e profissionais de Educação Física com relação à lógica interna das práticas motrizes, elaborou-se uma ferramenta de análise da lógica interna. A mesma foi estruturada em duas etapas: a primeira destinada à análise propriamente dita da lógica interna das práticas motrizes de interação; e a segunda dedicada à apresentação de um guia didático para o desenvolvimento de determinada prática a partir das características evidenciadas na análise, como exposto na Figura 2. O objetivo dessa estruturação é que o professor e profissional analise a lógica interna da prática motriz elegida e consiga pensar em estruturas de atividades que contemplem essas características, a partir do guia didático. 
Figura 2 - Ferramenta de análise da lógica interna de práticas motrizes de interação.

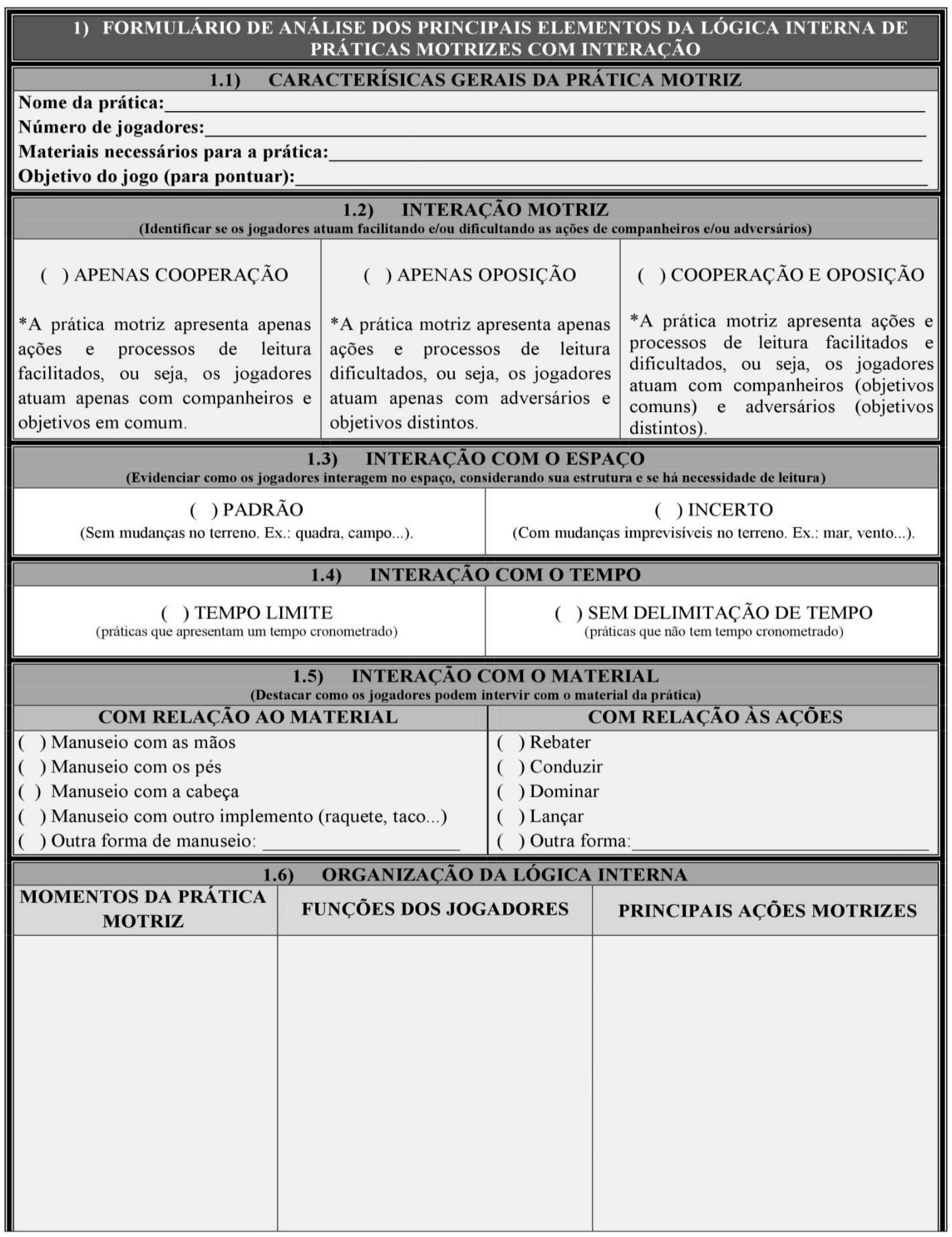


2) GUIA DIDÁTICO PARA O TRATO PEDAGÓGICO COM AS PRÁTICAS MOTRIZES DE INTERAÇÃO

\section{1) CARACTERÍSICAS GERAIS DA PRÁTICA MOTRIZ}

Esses elementos específicos da prática motriz são as primeiras características que se devem evidenciar a partir das regras. Esses aspectos orientarão os principais elementos da organização didático-pedagógica, em especial no planejamento da aula, no que se referem aos materiais necessários, as características das atividades propostas, a disposição do número de aluno da turma com relação ao número de jogadores da prática, entre outros aspectos de ordem estrutural.

\section{2) INTERAÇ̃̃O MOTRIZ}

\section{APENAS COOPERAÇÃO}

Exemplos:

Ginástica de Competição em Equipes Ginástica Rítmica de Conjunto,

Ginástica Aeróbica

Ginástica Acrobática

Remo

Vela

Frescobol

Dança de Salão

Revezamento

Práticas motrizes exclusivamente cooperativas que demandam organização de todos os participantes para que se atinja o objetivo necessário. Isso implica em processos de interpretação e realização das ações de forma facilitada, ou seja, os alunos atuam auxiliando uns aos outros, sem interferência de adversários em suas ações. Para o trato pedagógico desse tipo de prática, devem-se estruturar atividades em que os alunos compreendam a importância de facilitar as ações do(s) companheiro(s) para o êxito das tarefas da prática motriz, elementos substanciais para o processo de ensino-aprendizagem. As jogadas combinadas e as sequências de ação pré-determinadas são as principais características desse tipo de prática motriz. Quanto melhor for estabelecido esse processo cooperativo, melhor será a qualidade das ações e dos processos de interpretação, tomada de decisão e antecipação dos alunos, aumentando as chances deles atingirem a eficiência necessária, tanto tática quanto técnica, para atuarem nessa prática motriz.

Práticas motrizes exclusivamente opositivas apresentam unicamente presença de adversário, seja um contra um ou todos contra todos, caracterizando práticas motrizes com foco na disputa. Isso implica em processos de interpretação e realização das ações de forma dificultada, ou seja, os alunos atuam dificultando as ações do(s) adversário(s), sem a presença de ações cooperativas. Para o trato pedagógico desse tipo de prática, devem-se estruturar atividades em que os alunos compreendam a importância de dificultar as ações dos seus adversários para o êxito das tarefas da prática motriz. A imprevisibilidade e a busca por superar as ações do(s) adversário(s) são as características mais marcantes desse tipo de prática motriz e precisam estar presentes no processo de ensino-aprendizagem. Quanto mais imprevisíveis forem as ações do jogador e maior for sua capacidade de interpretação da leitura do(s) adversário(s), mais chances eles apresentarão de superá-los, objetivo principal de práticas motrizes dessa natureza.

Práticas motrizes que apresentam ações de cooperação e oposição ao mesmo tempo. Isso implica em processos de interpretação e realização das ações de forma facilitada para companheiro(s) e dificultada para adversário(s). Isso demanda tomadas de decisão apuradas para atuação na prática motriz, visto a complexidade e velocidade dos processos interpretação das ações do(s) companheiro(s) e adversário(s). Para o trato pedagógico desse tipo de prática, devem-se estruturar atividades em que os alunos entendam a importância de facilitar as ações dos seus companheiros e dificultá-las para os adversários, bem como perceba que suas ações são constantemente analisadas por essa complexa trama de relações de cooperação e oposição. Tanto jogadas combinadas e sequências de movimento quanto imprevisibilidade e superação do adversário são as principais características desse tipo de prática motriz. Partindo disso, é necessário que o processo de ensino-aprendizagem considere essas características, principalmente identificando as situações cooperativas e opositivas em cada momento da prática motriz. Elementos como tomada de decisão, interpretação, antecipação e percepção são importantes para atuação nessas práticas motrizes. Desenvolver essas capacidades aumentam as chances dos alunos atingirem a capacitação necessária, desde o ponto de vista da ação até as complexas situações-problema que se apresentam.

Esportes Coletivos (voleibol, futebol, futsal, basquete, handebol...)

Tênis em Duplas 


\begin{tabular}{|c|c|}
\hline \multirow{2}{*}{\multicolumn{2}{|c|}{$\begin{array}{l}\text { 2.3) INTERAÇ̃̃O COM O ESPAÇO } \\
\text { Em práticas motrizes em meio padrão, não há necessidade de leitura específica } \\
\text { do(s) jogador(es) com relação à possíveis alterações no terreno de prática. } \\
\text { Com isso, as atividades propostas no processo de ensino-aprendizagem podem } \\
\text { apresentar um foco maior nas possibilidades de relações espaciais que a } \\
\text { própria prática apresenta. Isso significa desenvolver a compreensão espaço- } \\
\text { temporal do aluno, vinculada à realização das ações e dos processos de } \\
\text { cooperação e/ou oposição, a partir das características da prática motriz } \\
\text { Tamanho de tatames, solos, ringues, quadras ou aparelhos específicos podem } \\
\text { ser enfatizados, desenvolvendo no aluno noções espaço-temporais que serão } \\
\text { importantes para sua atuação efetiva. }\end{array}$}} \\
\hline & \\
\hline ESPACCO INCERTO & $\begin{array}{l}\text { Em práticas motrizes em meio incerto, há necessidade de leitura constante } \\
\text { do(s) jogador(es) em relação às alterações no terreno de prática, mais presente } \\
\text { em atividades ao ar livre. Nesse sentido, o processo de ensino-aprendizagem } \\
\text { precisa considerar essas modificações do espaço, principalmente no que se } \\
\text { refere à compreensão dos alunos na importância da interpretação desses } \\
\text { elementos para atuar na prática motriz. Além disso, é necessário que o aluno } \\
\text { consiga adaptar as suas ações e as suas tomadas de decisão de forma coerente } \\
\text { com as alterações que o meio de prática expressa. Características como maré, } \\
\text { correntes de ar, alterações climáticas, entre outros fenômenos naturais que } \\
\text { interferem diretamente nas ações dos jogadores, precisam ser consideradas e, } \\
\text { se possível, simuladas nos processos de ensino-aprendizagem. }\end{array}$ \\
\hline \multicolumn{2}{|r|}{$\begin{array}{ll}\text { 2.4) } & \text { INTERAÇÃO COM O TEMPO }\end{array}$} \\
\hline \multicolumn{2}{|r|}{$\begin{array}{l}\text { Essas práticas motrizes caracterizam-se por ter um tempo cronometrado para } \\
\text { sua realização. Isso significa que as ações e as tomadas de decisão precisam } \\
\text { ser realizadas com a pressão temporal expressa pela prática. Tendo em vista } \\
\text { essa especificidade, o processo de ensino-aprendizagem precisa adaptar-se a } \\
\text { essas delimitações temporais. Para isso, podem-se propor atividades em que as } \\
\text { ações devam ser realizadas em determinado espaço de tempo, remetendo } \\
\text { diretamente as características da prática motriz. }\end{array}$} \\
\hline $\begin{array}{l}\text { SEM DELIMITAÇÃO DE } \\
\text { TEMPO }\end{array}$ & $\begin{array}{l}\text { Práticas motrizes sem delimitação de tempo costumam ser controladas por } \\
\text { pontuações específicas. No entanto, isso não significa que as questões } \\
\text { temporais não sejam importantes para essas práticas motrizes. É importante } \\
\text { que o processo de ensino-aprendizagem considere as pressões de tempo que a } \\
\text { lógica interna da própria prática condiciona. Isso significa que considerar os } \\
\text { aspectos temporais de uma prática não está obrigatoriamente vinculado a um } \\
\text { tempo cronometrado. Essa relação pode expressar-se na capacidade de } \\
\text { percepção temporal com relação às demandas que as características da própria } \\
\text { prática motriz condicionam, como a realização de uma ação antecipada ao } \\
\text { comportamento de um adversário ou com relação às próprias alterações do } \\
\text { ambiente, entre outros exemplos. }\end{array}$ \\
\hline \\
\hline \multicolumn{2}{|r|}{$\begin{array}{l}\text { INTERAÇ̃̃O COM O MATERIAL } \\
\text { Identificar a forma de manuseio do material da prática é essencial para que o } \\
\text { professor consiga propor atividades condizentes com a lógica interna da } \\
\text { prática motriz. Indica-se que todas as atividades, inclusive o aquecimento, } \\
\text { busque manter a característica essencial da forma como os jogadores } \\
\text { interagem com o material. Isso ganha sentido ao considerar que quanto mais } \\
\text { oportunidades de se relacionar com o material o jogador tenha, maior será a } \\
\text { probabilidade deles obterem sucesso na realização dessas ações. Não significa } \\
\text { que todas as atividades tenham que ter o foco nas ações, mas sim que as } \\
\text { situações propostas pelo professor conservem a forma como o jogador interage } \\
\text { com o material nas diferentes situações expressas pela prática motriz. }\end{array}$} \\
\hline COM RELAÇÃO ÀS AÇÕES & $\begin{array}{l}\text { Mesmo após identificar a forma de relacionar-se com o material, é necessário } \\
\text { delimitar a habilidade motora que as ações de determinada prática motriz }\end{array}$ \\
\hline
\end{tabular}




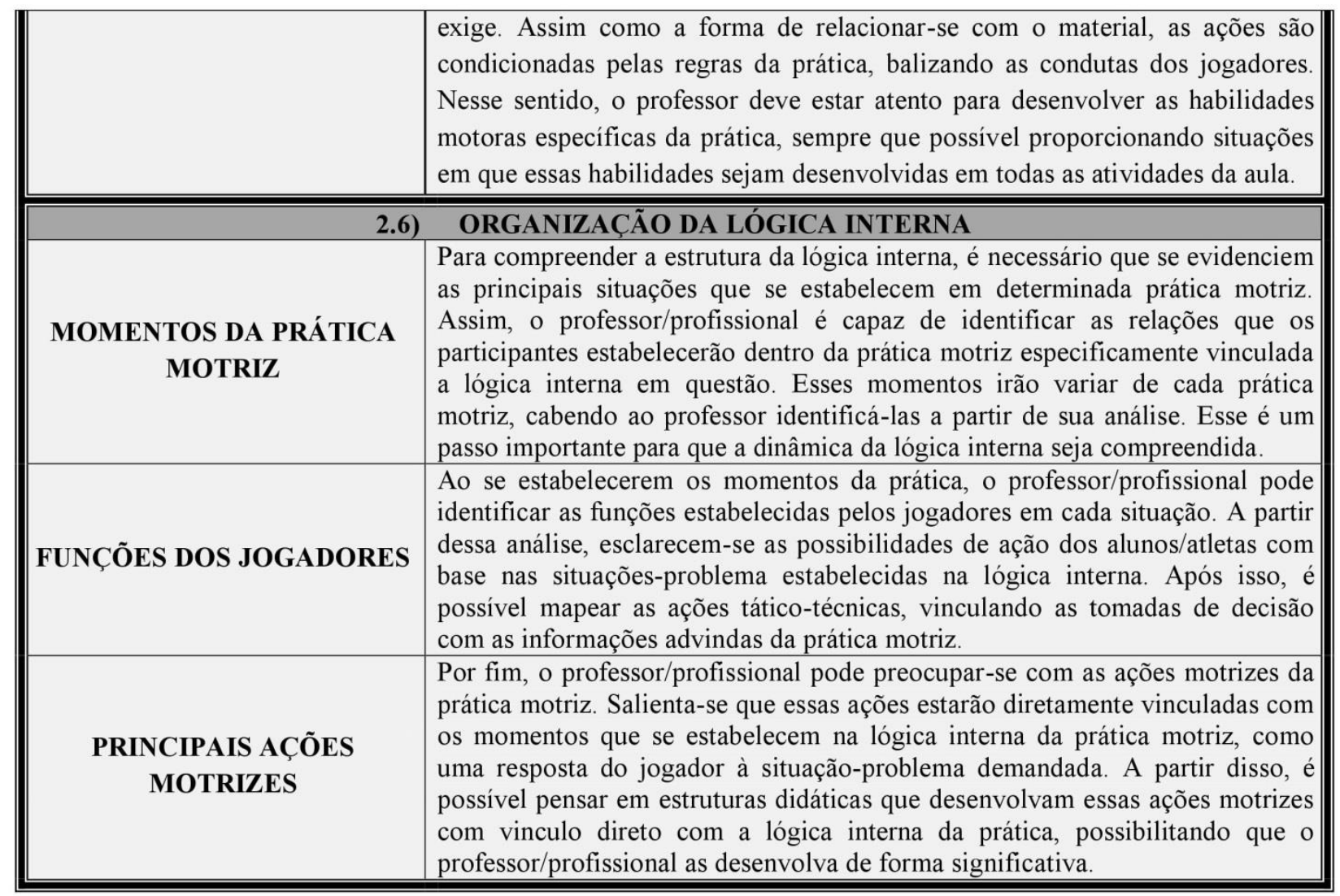

Fonte: Elaborado pelos autores

Após a apresentação da ferramenta, são necessárias algumas considerações quanto à finalidade e o lugar que esse material pode ocupar na prática pedagógica de professores e profissionais de Educação Física. Mesmo apontando elementos relevantes da lógica interna das práticas motrizes de interação, essa ferramenta não objetiva, em hipótese alguma, substituir o enfoque do processo de ensino-aprendizagem, tampouco se apresenta como uma abordagem da Educação Física. Estruturou-se a Figura 3 para esclarecer o papel desse instrumento no processo de ensino-aprendizagem. 
Figura 3 - O lugar da ferramenta de análise da lógica interna no processo de ensino-aprendizagem de práticas motrizes de interação

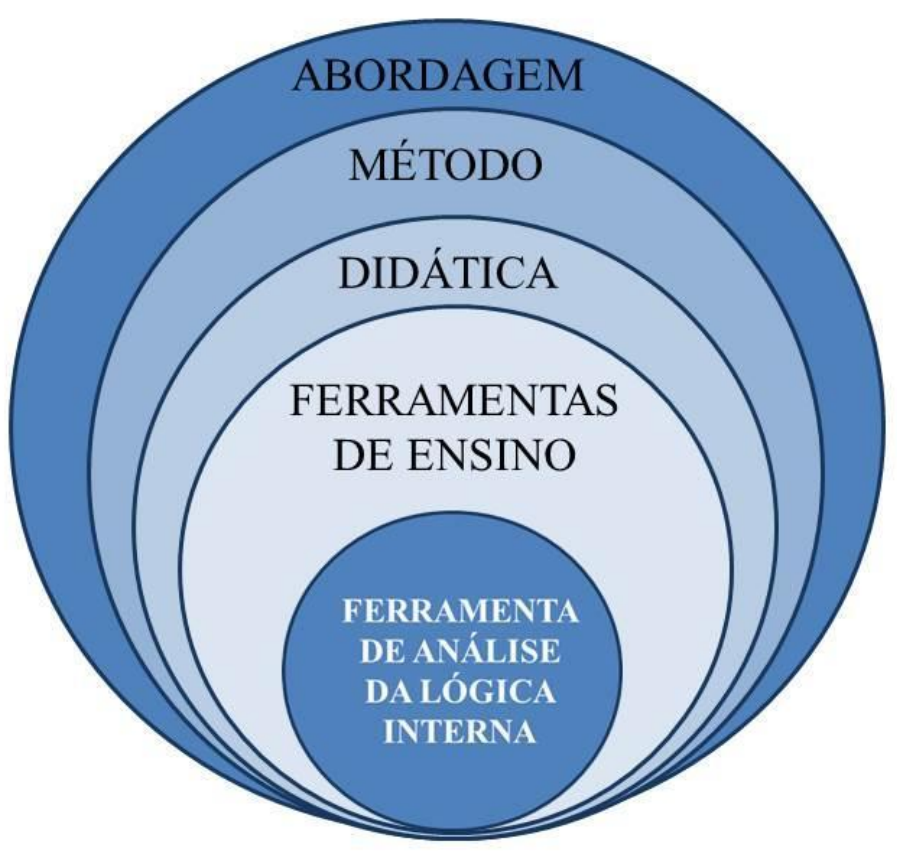

Fonte: Elaborado pelos autores.

Tendo em vista essa esquematização, enfatiza-se que a ferramenta de análise da lógica interna apresenta-se como um dos instrumentos que o professor e profissional pode utilizar em sua prática pedagógica, desde que sua utilização esteja orientada pelos princípios de sua abordagem, do método escolhido e da organização didática estabelecida, considerando a abrangência de cada um deles. Esses aspectos, primordiais para o processo de ensinoaprendizagem, serão os responsáveis por guiar e dar o tom às atividades propostas pelos professores e profissionais. Isso significa que a ferramenta, por si só, não dá conta do processo de ensino-aprendizagem como um todo, ela apenas identifica os elementos que derivam da lógica interna das práticas motrizes. Os aspectos pedagógicos, metodológicos e didáticos ficam a cargo do professor e do profissional que utilizarem a ferramenta.

Entretanto, destaca-se que há conhecimentos mínimos sobre a lógica interna de práticas motrizes de interação que devem ser tematizados em aulas. É nesse sentido que se concretiza a necessidade e a relevância dessa ferramenta para a prática pedagógica da Educação Física, ao passo que ela possibilita desvelar essas características da prática motriz e, ao mesmo tempo, serve como guia para a prática pedagógica.

Com essa compreensão, constata-se que independentemente da abordagem, do método e dos princípios didáticos elegidos, esses elementos precisam ser tematizados, visto que são referentes à própria especificidade das manifestações socioculturais que compõem a Educação Física. Não obstante, esses conhecimentos da lógica interna de cada prática motriz serão desenvolvidos sob a ótica dos princípios pedagógicos, metodológicos e didáticos, os quais serão enfatizados a partir das concepções de Educação Física, mundo e sociedade de cada professor. Salienta- 
se que a ferramenta de análise da lógica interna foi desenvolvida, prioritariamente, por propostas que propõem o ensino por meio da dinâmica do jogo e compreendem as práticas motrizes como fenômenos socioculturais, inserindo-os no processo de ensino-aprendizagem de forma crítica e reflexiva.

\section{Considerações finais}

Nesta pesquisa foi apresentada uma ferramenta de análise da lógica interna das práticas motrizes, com a intenção de subsidiar a prática pedagógica de professores e profissionais de Educação Física. Como mencionado, a mesma foi estruturada em duas etapas sendo a primeira destinada à análise propriamente dita da lógica interna das práticas motrizes de interação e a segunda dedicada à apresentação de um guia didático para o desenvolvimento de determinada prática a partir das características evidenciadas na análise. Salienta-se que a ferramenta se apresenta como um dos instrumentos que o professor pode empregar em sua prática pedagógica, desde que sua utilização esteja orientada pelos princípios de sua abordagem, do método escolhido e da organização didática estabelecida, considerando a abrangência de cada um deles.

A partir do que foi apresentado, acredita-se que existem dois caminhos a serem seguidos após o momento inicial de criação da ferramenta. O primeiro deles é realizar a aplicação da ferramenta de análise da lógica interna, a fim de visualizar como esta se materializa na prática. O segundo caminho é avaliar a opinião dos professores atuantes em diversos contextos sobre a ferramenta, de modo a visualizarmos mais elementos para melhor compreendê-la e, eventualmente, fazer novas adaptações.

\section{Referências}

BRACHT, Valter. Educação Física \& Ciência: Cenas de um casamento (in)feliz. Ed. Unijuí, 1999.

BRACHT, Valter. Educação Física: Qual a especificidade? In: Anais do XVI ENDIPE - Encontro Nacional de Didática e Práticas de Ensino, 2012. Anais eletrônicos. Campinas, UNICAMP, 2012. Disponível em: 〈http://www.infoteca.inf.br/endipe/smarty/templates/arquivos_template/upload_arquivos/acervo/docs/0033s.pdf $>$. Acesso em: 07 out. 2018.

BRASIL. Base Nacional Comum Curricular. Proposta preliminar. Segunda versão revista. Brasília: MEC, 2016. Disponível em: 〈http://basenacionalcomum.mec.gov.br/download-da-bncc〉. Acesso em: $11 \mathrm{dez} .2018$.

DAÓLIO, Jocimar. Educação Física e o conceito de cultura. Autores associados, 2004.

DEMO, Pedro. Metodologia do Conhecimento Científico. São Paulo. Ed. Atlas, 2000.

FAGUNDES, Felipe Menezes; RIBAS, João Francisco Magno. A dinâmica do voleibol sob as lentes da Praxiologia motriz: uma análise praxiológica do levantamento. Revista Brasileira de Ciência \& Movimento, v. 25, n. 3, p. 134-149, 2017.

FRANCHI, Silvester. Princípios Didático-metodológicos para o Trabalho Pedagógico com Jogos Tradicionais. 2017. 85f. Dissertação de Mestrado - UFSM, Santa Maria, 2017.

GIL, Antônio Carlos. Métodos e técnicas de pesquisa social. 6. ed. São Paulo. Ed. Atlas, 2008. 
HERNÁNDEZ MORENO, J.; RODRÍGUEZ RIBAS, J. P. La Praxiologia Motriz: fundamentos y aplicaciones. Barcelona - Espanha: INDE Publicaciones, $1^{\text {a }}$ ed., 2004.

KUNZ, Elenor. Transformação didático-pedagógica do esporte. Ed. Unijuí, 2006.

LAGARDERA, Francisco Otero; LAVEGA, Pere Burgués. Introducción a la Praxiología Motriz. Barcelona: Paidotribo, 2003.

LANES, Bruno Minuzzi. Ensino-Aprendizagem-Treinamento do Voleibol: Proposições a partir da Praxiologia Motriz e o Método Situacional. 2018. 169f. Dissertação de Mestrado - UFSM, Santa Maria, 2018.

MARQUES FILHO, C. V. A estruturação do futebol e seus elementos pedagógicos: uma visão a partir da praxiologia motriz. 2017. 82f. Dissertação de Mestrado - UFSM, Santa Maria 2017.

OLIVEIRA, Raquel Valente de; RIBAS, João Francisco Magno; GOMES-DA-SILVA, Piere Normando. Relação entre o praxema e as interações motrizes: implicações nos processos de leitura de jogo e tomada de decisão nos jogos esportivos coletivos. Pensar a Prática, v. 21, n. 2, 29 jun. 2018.

PARLEBAS, Pierre. Elementos de sociologia del deporte. Málaga: Andalucia. 1988.

RIBAS, João Francisco Magno (Org.). Praxiologia Motriz e voleibol: elementos para o trabalho pedagógico. Ijuí: Editora da Unijuí, 2014.

SILVA, Sabrine Damian da. Jogos Tradicionais organizados no estado do Rio Grande do Sul: uma aproximação etnomotriz. 2015. 185f. Dissertação de Mestrado - UFSM, Santa Maria 2015.

SOARES, Carmen Lúcia et al. Metodologia do ensino de Educação Física. Cortez Editora, 1992.

\section{Como citar este artigo}

FAGUNDES, Felipe Menezes; FOLLMANN, Natiele; WENZEL, Vanessa Ines. Como identificar a lógica interna das práticas motrizes de interação? uma proposta de ferramenta de análise a partir da praxiologia motriz. Revista Kinesis, Santa Maria, v. 37, p.01-15, 2019. 